\title{
THE EFFICIENCY OF INVESTMENT \\ IN THE PRESENCE OF \\ AGGREGATE DEMAND SPILLOVERS
}

Andrei Shleifer

Robert Vishny

Working Paper No. 2297

NATIONAL BUREAU OF ECONOMIC RESEARCH

1050 Massachusetts Avenue

Cambridge, MA 02138

June 1987

We are indebted to Peter Diamond, Kevin M. Murphy, David Romer, and Lawrence $H$. Summers for helpful comments. Shleifer is grateful to Graduate School of Business, University of chicago, for its hospitality. The research reported here is part of the NBER's research program in Financial Markets and Monetary Economics. Any opinions expressed are those of the authors and not those of the National Bureau of Economic Research. 


\title{
The Efficiency of Investment in the Presence of Aggregate Demand Spillovers
}

\begin{abstract}
$\underline{\text { ABSTRACT }}$
In the presence of aggregate demand spillovers, an imperfectly competitive firm's profit is positively related to aggregate income, which in turn rises with profits of all firms in the economy. This pecuniary externality makes a dollar of a firm's profit raise aggregate income by more than a dollar, since other firms' profits also rise, and in this way gives rise to a "multiplier." Since such "multipliers" are ignored by firms making investment decisions, privately optimal investment choices under uncertainty will not in general be socially optimal. Under reasonable conditions, private investment is too low.
\end{abstract}

Andrei Shleifer Graduate School of Business University of Chicago 1101 East 58th Street Chicago, IL 60637
Robert Vishny

Graduate School of Business University of Chicago 1101 East 58th Street Chicago, IL 60637 


\section{Introduction}

This paper analyzes investment decisions in the presence of macroeconomic externalities. Following the work of Cooper and John (1985) and Blanchard and Kiyotaki (1985), 1 we study a model with aggregate demand spillovers, where a firm's profit is positively related to aggregate income, which in turn rises with profits of all firms in the economy. This externality makes a dollar of a firm's profit raise aggregate income by more than a dollar, since other firms' profits also rise, and similarly a dollar of a firm's loss reduce income by more than a dollar. Equivalently, there is a "multiplier" on a firm's profit (or loss) in the determination of aggregate income. Moreover, such multipliers vary across states of nature, depending on how many other firms benefit from a firm's profit (or lose from its loss) In each state. Because firms ignore this variation of multipliers across states in making investment decisions, profit maximizing choices need not be socially optimal.

To set up a benchmark for evaluating economies with imperfectly informed firms, Section 2 presents a full information economy. In the model, each sector has a potential monopolist with access to a cost reduction technology. Each monopolist must decide whether to invest and obtain a low marginal cost or leave the market to a competitive fringe that has a higher marginal cost. The profit-maximizing choice depends on expected demand, since only in a large enough market can an investment in unit cost reduction break even. Demand, in turn, depends on profits of other sectors, since profits are distributed to the consumer and spent by him. Aggregate demand spillovers

\footnotetext{
${ }^{1}$ Also related are papers by Diamond (1982), Hart (1982), Weitzman
} (1982), Heller (1985), Shleifer (1986) and Mankiw (1986). 
through the distribution of profits make firms interested in the productive potentials of firms in other sectors of the economy.

In Section 2, the realized distribution of cost reduction technologies across sectors is publicly known. This knowledge enables each potential nonopolist to compute the profits of potential monopolists in other sectors and in this way to forecast aggregate profits and demand. He can then gauge the size of his own market and make an accurate investment decision. In the benchmark case of perfect information, the economy has a unique perfect foresight equilibrium in which investment decisions are efficient. In other words, a perfectly informed planner would have each firm make the same investment decision as it does in the free market equilibrium.

In contrast, Section 3 presents the same economy, except now firms have imperfect knowledge about cost reduction opportunities of other sectors. Firms then have to make forecasts of aggregate demand based on their priors as well as observation of their own technological opportunities. In this case, rational expectations equilibria exist, but are not, in general, unique or efficient. The sources of inefficiency are twofold. The first is the inability of firms to accurately condition their investment choices on circumstances of other sectors, since decisions must be made on the basis of imperfect information. An equally well-informed social planner would face the same difficulty.

The second source of inefficiency stems from the divergence of profitmaximizing and constrained welfare-maximizing investment decisions in the presence of aggregate demand spillovers. A firm's losses (profits) have an adverse (beneficial) impact on profits of other firms, and the firm ignores this impact in making investment decisions. Interestingly, this externality 
has no adverse welfare consequences in the certainty model of Section 2 . This is because there a firm has a positive spillover effect on other firms if and only if it makes a positive profit by investing. In the uncertainty case, in contrast, it is not the case that when a firm's profit averages to zero across states, its spillover effect also averages to zero.

To see this, consider a marginal firm that expects to break even on average if it invests. When the state of the world turns out to be good, many other firms are investing in cost reduction and the marginal firm's positive profit raises profits in all these sectors, giving its profits a high multiplier in the generation of aggregate income. When the state of the world turns out to be bad, only a few firms are investing in cost reduction, and the loss by the marginal firm spills over onto the profits of only a few firms, making the multiplier on that loss small. Overall, even though the marginal firm expects on average to break even, the impact of its decision to invest on expected aggregate income is strictly positive. In this way, uncertainty about the productive potential of the economy in the presence of aggregate demand spillovers gives rise to systematic underinvestment.

\section{The Tull Information Economy}

The benchmark economy described in this section sets the stage for the subsequent analysis. It shares with the models to follow the assumptions about preferences, technology, and markets, but uses a particularly simple information structure.

Consider a one period economy with a representative consumer, who has Cobb-Douglas preferences defined over a unit interval of goods. All goods have the same expenditure shares. Thus, when his incone is $y$, the consumer can be thought of as spending $y$ on every commodity. The consumer is endowed 
with L units of labor, which he supplies inelastically, and he owns all the profits of this economy. Taking his wage as numeraire, his budget constraint is given by:

\section{(1) $y-I I+L$,}

where II is aggregate profits.

Each good is produced in its own sector, and each sector consists of two types of firms. First, each sector has a competitive fringe of firms which convert one unit of labor input into one unit of output with a constant returns to scale technology. In addition, each sector has a unique firm that has access to a cost reduction technology. This firm is alone in having access to that technology in its sector, and hence will be referred to as a monopolist (even though, as we specify below, it does not always operate). Cost reduction requires the input of $F$ units of labor (required outlay) where $F$ is drawn from the economy-wide distribution $H(F)$ and allows each unit of labor to produce $\alpha>1$ units of output. In this section, it is publicly known that $H(F)$ is the realized distribution of required outlays across sectors. Much of this paper examines the consequences of uncertainty about the realized distribution $\mathrm{H}$.

The monopolist in each sector decides whether to becone a low cost firm or to abstain from production altogether. He reduces his costs ("Invests") only if he can earn a profit. The price he charges if he produces equals unity, since he loses all his sales to the fringe if he charges more, and he would not want to charge less when facing a unit elastic demand curve. When income is $y$, the profit of a monopolist who spends $F$ to reduce costs is:

(2) $x-\frac{\alpha-1}{\alpha} y-F=a y-F$. 
The monopolist invests as long as $y \geq F / a$. It is obvious from this that, in equilibrium, assuming all firms expect the same aggregate income, if a firm with required outlay $F$ invests, then all firms with required outlays less than $F$ also invest. We assume that $a \cdot L-F_{\min }>0$, where $F_{\min }$ is the lower end of the support of $H$; that is, it always pays the best cost reducer to invest.

A perfect foresight equilibrium in this economy is given by the marginal firm with required outlay $F^{*}$ and income $y\left(F^{*}\right)$ such that (a) income $y\left(F^{*}\right)$ obtains when all firms with required outlays no greater than $F^{*}$ invest, and (b) the marginal firm breaks even, i.e.,

(3) $\quad a y\left(F^{*}\right)-F^{*}=0$.

When all firms with required outlays no greater than $F^{*}$ invest, then aggregate profits are given by:

(4) $\Pi\left(F^{*}\right)=\int_{F_{\min }}^{F^{*}}\left[\operatorname{ay}\left(F^{*}\right)-F\right] d H(F)-\operatorname{ay}\left(F^{*}\right) H\left(F^{*}\right)-\int_{F_{\min }}^{F^{*}} F d H(F)$.

Combining (4) and (1), we obtain the expression for income:

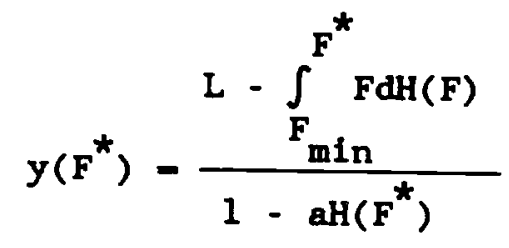

Equilibrium obtains at $F^{*}$ if (3) holds for income given by (5).

The numerator of expression (5) is the amount of labor used in the economy for actual production of output, after investment outlays. One over the denominator is the multiplier that recognizes that an increase in 
effective labor raises income by more than one for one, since expansion of low cost sectors also raises profits. To see this more explicitly, one can calculate that:

(6) $\frac{\mathrm{dy}\left(F^{*}\right)}{\mathrm{dF}}=\frac{\pi\left(F^{*}\right) \mathrm{dH}\left(F^{*}\right)}{1-\mathrm{aH}\left(F^{\star}\right)}$

where $\pi\left(F^{*}\right)$ is the profit of the marginal firm. When the marginal firm earns this profit, it distributes it to shareholders, who in turn spend it on all goods and thus raise profits of all cost reducing firms in the economy. The effect of the marginal firm's profit is therefore enhanced by the increases in profits of all cost reducing firms resulting from increased spending. Since there are $H\left(F^{*}\right)$ of such firms, the multiplier is increasing in the number of firms that benefit from the spillover of the marginal firm. The more firms invest, the greater is the cumulative increase in profits and therefore income resulting from a positive NPV investment by a marginal firm.

For an alternative interpretation of (6), notice that since the price of labor is unity, the profit of the marginal firm, $\pi\left(F^{*}\right)$, is exactly equal to the net labor saved from its investment in cost reduction. The numerator of (6) is therefore the increase in labor available to the economy as a result of the investment by the $F^{*}$-firm in the cost reduction technology. In equilibrium, this freed up labor moves into all sectors. However, its marginal product is higher in investing sectors than in non-investing sectors. The more sectors investing in cost reduction (1.e., the higher is $H\left(F^{*}\right)$ ), the greater is the increase in total output resulting from the inflow of freed up labor into these sectors. In fact, the denominator of (6) is just the average of marginal labor costs across sectors, which is clearly a 
decreasing function of $H\left(F^{*}\right)$. This interpretation connects (6) to (5), which explicitly states that income is a multiple of productive labor, and that the multiplier is increasing in $H\left(F^{*}\right)$.

Proposition 1: The equilibrium exists and is unique. The number of firms investing in cost reduction is efficient at the given prices.

\section{Proof:}

Notation: Denote by $\pi\left(F \mid F^{*}-F\right)$ the profit of the firm with required outlay $F$ when only the firms with required outlays no greater than $F$ invest. Call the investing firm with the highest required outlay the marginal firm. (a) Existence: Note that $\pi\left(F_{\min } \mid F^{*}-F_{\min }\right)-a L-F_{\min }>0$. Either $\pi\left(F_{\max } \mid F^{*}-F_{\max }\right) \geq 0$, in which case every firm investing is an equilibrium, or $\pi\left(F_{\max } \mid F^{*}-F_{\max }\right)<0$, In which case there exists an $F$ such that $\pi\left(F \mid F^{*}-F\right)=0$ by the intermediate value theorem.

(b) Uniqueness: Investment by a firm making a negative profit reduces aggregate income. Take an equilibrium with marginal firm $F^{*}$. Now raise the number of investing firms in order of the magnitude of their required outlays, starting with those just above $F^{*}$. Since $F^{*}$ firms break even at the initial equilibrium, firms with $F>F^{*}$ lose money. Adding them can only reduce aggregate income, making investments by each additional firm even more unprofitable. To find another equilibrium, however, income must be raised so that a new marginal firm, with required outlay $F^{\star *}>F^{*}$ can break even. Since adding investing firms with required outlays above $F^{*}$ only reduces income, this is impossible.

(c) Efficiency: An investing firm adds to aggregate income (and therefore, at constant prices, to welfare) if and only if the firm's profits are 
positive. Consider an investment rule in which some (possibly empty) subset of firms with $F<F^{*}$ do not invest and some (possibly empty) subset with $F>F^{*}$ do invest. Since all those with $F<F^{*}$ are making a positive profit in the $F^{*}$ equilibrium, eliminating any of them only decreases income. Now consider adding some firms with $F>F^{*}$ in ascending order of their $F^{\prime} s$. Since income is no higher after eliminating some subset of firms with $F<F^{*}$, the lowest $F>F^{*}$ firms will make a negative profit from investing. This further decreases income, making investment by firms with higher F's even more unprofitable.

The efficiency result deserves a comment. According to expression (6), a firm's spillover is positive if and only if its own profits are positive. Therefore, even though a firm deciding whether or not to reduce its unit cost ignores the spillover, it decides to do so only when the social planner would choose likewise. The multiplier only changes the magnitude of the effect of a firm's investment on income, and not the sign. Under certainty, both second-best (constrained by monopoly pricing) welfare maximization and profit maximization dictate that an investment be undertaken if and only if it earns a positive profit. In the rest of the paper, we show that, under uncertainty, this need not be the case. Specifically, if a firm's profit across states averages to zero, its average spillover effect on other firms is in general positive.

\section{The Incomplete Information Yode1}

Suppose now that there are two states of the world, characterized by different distributions of required outlays across sectors. In the good state, the distribution is $G(F)$, in the bad state, it is $B(F)$. Assume that 
the densities $g(F)$ and $b(F)$ are strictly positive and continuous on $\left[F_{\min }, F_{\max }\right]$ and that the likelihood ratio $b(F) / g(F)$ is strictly increasing in F on that interval. That is, the relative likelihood of a higher fixed cost is higher in the bad state. This implies, in particular, that $G(F)>B(F)$ for all $F$ in $\left(F_{\min }, F_{\max }\right)$.

The probability that the state is good is denoted by $p$; it is a common prior of all market participants. In this section, each potential monopolist also observes his own required outlay $F$, but does not know which state is realized. For this reason, he must form a posterior belief, $q(F)$, that the state is good:

(7) $\quad q(F)=\frac{p g(F)}{p g(F)+(1-p) b(F)}$.

Because the likelihood ratio $b(F) / g(F)$ is assumed to be increasing in $F, q(F)$ is decreasing in $F$ for any prior $p$. The higher is the required outlay that a firm draws, the lower is the probability it attaches to the outcome of a good state.

When a firm conjectures that income is $y_{g}$ in the good state, and $y_{b}$ in the bad state, it invests provided

$$
\left.a_{l y(F) y_{g}}+(1-q(F)) y_{b}\right]-F \geq 0
$$

Because profits in each state are linear in income, all that a firm cares about in its investment decision is the average level of income it expects.

A rational expectations equilibrium is defined as a cutoff required outlay $F^{*}$ of the marginal firm, and incomes in the good and bad state $y_{g}\left(F^{*}\right)$ and $y_{b}\left(F^{*}\right)$ given by $(5)$ using $G(F)$ and $B(F)$ respectively, such that the marginal firm expects to break even. To a firm with required outlay $F$, expected income is: 


$$
y^{e}(F)-q(F) y_{g}\left(F^{\star}\right)+(1-q(F)) y_{b}\left(F^{*}\right) \text {. }
$$

Since $q(F)$ is decreasing in $F, y^{e}(F)$ is decreasing in $F$, and therefore firms with required outlays below $F^{*}$ always prefer to invest whenever the marginal firm expects to break even. In equilibrium, all agents agree on $F^{\star}$, and hence on incomes in the two states, but disagree on their relative likelihoods. The marginal firm must expect to break even using its own assessment of the probability that the state is good.

Proposition 2: Under incomplete information, there always exists at least one equilibrium. As long as not all firms invest in equilibrium, investment by some group of firms with required outlays above $F^{*}$ raises expected income. If there are multiple equilibria, the equilibrium with the highest $F^{*}$ is Pareto preferred to the others.

\section{Proof:}

(a) Existence: Consider the function $E\left[\pi\left(F \mid F^{*}-F\right)\right]$ under the assumption that $E\left[\pi\left(F_{\min } \mid F^{*}-F_{\min }\right)\right]>0$ and apply the intermediate value theorem. (b) Underinvestment: We show that, for any equilibrium cutoff level $\mathrm{F}^{*}$, there exists an $\varepsilon>0$ such that investment by the firms in the interval $\left(F^{*}, F^{*}+\varepsilon\right)$ raises expected income. We have:

$$
\frac{\mathrm{dE}(\mathrm{y})}{\mathrm{d} \varepsilon}(\varepsilon-0)-\frac{\mathrm{p} \cdot \mathrm{g}\left(\mathrm{F}^{*}\right) \cdot \pi_{\mathrm{g}}\left(\mathrm{F}^{*}\right)}{1-\mathrm{aG}\left(\mathrm{F}^{\star}\right)}+\frac{(1-\mathrm{p}) \cdot \mathrm{b}\left(\mathrm{F}^{*}\right) \cdot \pi_{\mathrm{b}}\left(\mathrm{F}^{*}\right)}{1-\mathrm{aB}\left(\mathrm{F}^{*}\right)} .
$$

Note that $\mathrm{Pg}\left(\mathrm{F}^{\star}\right) \pi_{\mathrm{g}}\left(\mathrm{F}^{*}\right)+(1-\mathrm{P}) \mathrm{b}\left(\mathrm{F}^{*}\right) \pi_{\mathrm{b}}\left(\mathrm{F}^{*}\right)-0$. However, $G\left(F^{*}\right)>B\left(F^{*}\right)$ and since $\pi_{g}\left(F^{*}\right)>0$ and $\pi_{b}\left(F^{*}\right)<0$, we conclude that $\frac{d E(y)}{d \varepsilon}(\varepsilon-0)>0$. 
(c) Pareto Ranking of Equilibria: Let $F_{1}^{\star}$ and $F_{2}^{*}$ be the cutoff levels for two different equilibria with $F_{1}^{*}<F_{2}^{*}$. Let $\Delta E(y)$ be the difference of expected incomes in the $F_{2}^{*}$ and $F_{1}^{*}$ equilibria; we show that $\Delta E(y)$ is positive. We have:

$$
\Delta E(y)=\frac{\mathrm{P}_{F_{1}^{*}} \pi_{\operatorname{good}}(F) d G(F)}{1-\operatorname{aG}\left(F_{1}^{*}\right)}+\frac{(1-\mathrm{p}) \int_{F_{1}^{*}}^{2} \pi_{\text {bad }}(F) d B(F)}{1-a B\left(F_{1}^{*}\right)}
$$

where $\pi_{\text {good }}(F)$ and $\pi_{\text {bad }}(F)$ are based on investment by all firms with required outlays less than $F_{2}^{*}$. But we must have that

$P \int_{F_{1}^{*}}^{F_{2}^{*}} \pi_{\operatorname{good}}(F) d G(F)+(1-P) \int_{F_{1}^{*}}^{F_{2}^{*}} \pi_{b a d}(F) d B(F)>0$ or else the firms between $F_{1}^{*}$ and $F_{2}^{*}$ would not be investing in the $F_{2}^{*}$ equilibrium. Since profits are positive in the good state and $G\left(F_{1}^{*}\right)>B\left(F_{1}^{*}\right)$, it follows that $\Delta E(y)$ is positive.

The logic of the underinvestment result warrants some elaboration. Since more firms invest in the good state, the positive profit that the marginal firm earns in that state spills over onto more investing firms than does the negative profit in the bad state. Put differently, the multiplier on the marginal firm's profit is higher in the good state. As a result, even when the marginal firms expect to earn zero, the expected change in income from investing is positive. 
Alternatively, consider the interpretation with change in productive labor. In the good state, the labor that is freed up and spread around as a result of the investment by the marginal firm goes to a large extent into the already investing sectors, where the marginal product of that labor is $h i g h$. In this state, a fraction $G\left(F^{*}\right)$ of that labor has high productivity. In the bad state, when productive labor is withdrawn from the economy as a result of investment by the marginal firm, only $B\left(F^{*}\right)$ of the sectors have invested to get high productivity. In other words, the labor released by the marginal firm in the good state is more productive than the labor absorbed by it in the bad state.

The difference between productivity of labor across states is not internalized by investing firms, however. Recall that an investing firm's profit is equal to the expected amount saved on its sector's wage bill from switching to the low marginal cost technology (at an initial cost of F) instead of leaving production to the fringe. But the value to the economy of the labor saved is equal to the wage payments to that labor plus the profit that labor produces elsewhere. In our model, the wage is constant and only the profit component of the value of labor saved varies across states. Firms ignore variation in this profit component when making their investment decisions. Since there are more sectors using labor to produce profits in good times, the profit of the marginal firm understates the true value of labor saved in good times more than it understates the value of extra labor used in bad times. On average, investment by a firm with zero expected profit raises the productive labor avallable to the economy, and is therefore preferred by the planner. 
The underinvestment result is a consequence of imperfect competition and aggregate demand spillovers in this economy, since we have made sure that the beliefs of the planner and of the marginal firm are the same. Ignorance about the state of nature is not, therefore, the only source of investment inefficiency in this model, since the equally well-informed planner would have more firms investing.

The underinvestment property of the model naturally leads to a multiplicity of equilibria in many cases. Multiplicity arises in the model when there is a group of marginal firms whose members make positive profits from investing if and only if (at least some) other members of the group invest. This situation occurs for a wide set of parameters, primarily because of the underinvestment property of the model.

Suppose we are at an equilibrium in which all firms having required outlays below $F^{*}$ invest. A firm with required outlay $F^{*}+\varepsilon$ will make a small negative profit if it invests by itself. On the other hand, if an entire interval of firms with required outlays slightly above $F^{*}$ invests, they will have a potentially large positive effect on average income, possibly making the decision to invest profitable for all firms in that interval. This would mean that there must be another equilibrium in which these firms invest. Hence, the property of the model that investment by a group of marginal firms raises income can be seen to lead to the existence of multiple equilibria.

Because this bootstrapping property relies on having different multipliers across states (and higher multipliers in good states), it is easy to see why we cannot get multiple equilibria in the one-period certainty model. But one could get the underinvestment property and the existence of multiple equilibria even in a world of certainty if investments generated 
more than one period of cash flows. In deciding whether or not to invest, firms would look at a discounted sum of cash flows, while the social planner would look at the same sum except with each period's cash flow weighted by the aggregate income multiplier for that period. Profit-maximizing firms would ignore variation in these multipliers across periods and might underinvest (overinvest) if their highest profits occurred in the periods when their spillover effects were largest (smallest).

One interesting application of the idea of inefficient investment due to variation of aggregate income multipliers over time is to rapidly developing economies. Suppose that to industrialize a sector the monopolist must incur the cost of a modern plant today but reaps the profits in future periods. His investment therefore absorbs current labor and releases future labor. If the economy is progressing, then it is probable that today's labor has less productive alternative uses than does future labor. But if productivity gains are mostly confined to a subset of imperfectly competitive industries, those gains may not be reflected in either lower prices or higher wages. This means that a larger portion of the value of future labor saved from investing in a modern plant than of current labor used to build it is accounted for by the profits of other sectors which the monopolist does not internalize. As a result, the monopolist's profitability calculation would place a lower relative value on future labor than would a social planner's. He might therefore choose not to invest even though it is socially optimal for him to do so. We conjecture that the internally generated level of investment in a rapidly developing economy characterized by rising aggregate income multipliers (profit spillovers) will be too low relative to the constrained optimum (that is, constrained by monopoly pricing in cost reducing sectors). 


\section{REFERENCES}

Blanchard, Olivier J. and Nobuhiro Kiyotaki (1985), "Monopolistic Competition, Aggregate Demand Externalities, and Real Effects of Nominal Money," NBER Working Paper 1770.

Cooper, Russell and Andrew John (1985), "Coordinating Coordination Failures in Keynesian Models," Cowles Foundation DP \#745, 1985.

Diamond, Peter A. (1982), "Aggregate Demand Management in Search Equilibrium," Journal of Political Economy, 90, pp. 881-895.

Hart, Oliver D. (1982), "A Model of Imperfect Competition with Keynesian Features, " Quarterly Journal of Economics, 97, pp. 100-138.

Heller, Walter P. (1985), "Coordination Failure Under Complete Markets with Application to Effective Demand," UCSD Mimeo.

Mankiw, N. Gregory (1986), "Monopolistic Competition and the Keynesian Cross," Harvard University Mimeo.

Shleifer, Andrei (1986), "Implementation Cycles," Journal of Political Economy, 94, Pp. 1163-1190.

Weitzman, Martin L. (1982), "Increasing Returns and the Foundations of Unemployment Theory," Economic Journal, 92, pp. 787-804. 